\title{
Avaliação de Aptidão Técnica e Socioambiental para Implantação de Parques Solares Fotovoltaicos com Sistema de Informação Geográfica - SIG
}

\author{
Tania Oliveira Escolano'; Vitor Ottoni Pastorel; Carlos Augusto Arentz Pereira \\ \escolanotania@gmail.com \\ 1. Universidade do Estado do Rio de Janeiro - UERJ.
}

Histórico do Artigo:

Recebido em: 25 de novembro de 2019 Aceito em: 20 de julho de 2020 Publicado em: 31 de agosto de 2020

\begin{abstract}
Resumo: 0 objetivo deste estudo visa indicar áreas mais aptas para a implantação de parques solares fotovoltaicos na microrregião Campo Maior, no estado do Piauí. Para esta análise foram considerados fatores socioambientais, infraestrutura e potencial solar por meio da utilização de Sistema de Informação Geográfica. Para a elaboração dos levantamentos de aptidão, foram utilizados bancos de dados públicos disponíveis, principalmente de bases cartográficas e imagens de satélite georreferenciadas. A partir destes dados foi elaborada uma matriz, na qual foram atribuídos pesos para cada variável de acordo com a importância e dimensão de cada fator. A avaliação utilizou análise multicritério e ferramentas computacionais baseadas em Sistemas de Informação Geográfica, de forma a obter um mapa de aptidão para a instalação de parques solares fotovoltaicos. A aptidão foi fortemente influenciada pelo potencial de irradiação solar (GHI) e pela proximidade às linhas de transmissão. A análise multicritério foi eficaz na identificação das áreas com maior potencial para implantação de empreendimentos solares fotovoltaicos. Observou-se que há sensível influência dos pesos atribuídos e da diversidade na resolução e margem de erro dos dados de entrada no mapa obtido. A inclusão de outras variáveis, como uma melhor calibração de pesos e uma maior precisão dos dados georreferenciados, são fatores fundamentais para obtenção de resultados mais precisos.
\end{abstract}

Palavras-chave: Energia solar fotovoltaica, Potencial para implantação, Geoprocessamento, Álgebra de mapas.

\section{Assessment of Technical and Socio-Environmental Suitability for Implementation of Photovoltaic Solar Parks With Geographic Information System - GIS}

\begin{abstract}
The objective of this study was to indicate areas that are better suited for the implantation of photovoltaic solar parks in the Campo Maior microregion, in the state of Piauí. For this analysis we considered socio environmental factors, infrastructure and solar potential through the use of Geographic Information System. For the elaboration of the aptitude surveys, available public databases were used, mainly of cartographic bases and georeferenced satellite images. From these data a matrix was elaborated, in which weights were assigned to each variable according to the importance and size of each factor. The evaluation used multicriteria analysis and computational tools based on Geographic Information Systems, in order to obtain an aptitude map for the installation of photovoltaic solar parks. Fitness was strongly influenced by solar radiation potential (GHI) and proximity to transmission lines. The multicriteria analysis was effective in identifying the areas with the greatest potential for the implementation of photovoltaic solar projects. It was observed that there is a significant influence of the assigned weights and diversity on the resolution and margin of error of the input data in the map obtained. The inclusion of other variables, better weight calibration and greater accuracy of georeferenced data are key factors for obtaining more accurate results.
\end{abstract}

Keywords: Photovoltaic Solar Energy, Potential for deployment, Geoprocessing, Map algebra. 


\section{Evaluación de la Idoneidad Técnica y Socioambiental para la Implementación de Parques Solares Fotovoltaicos con Sistema de Información Geográfica - SIG}

Resumen: El objetivo de este estudio fue indicar las áreas más adecuadas para la implantación de parques solares fotovoltaicos en la microrregión de Campo Maior, en el estado de Piauí. Para este análisis consideramos factores socioambientales, infraestructura y potencial solar mediante el uso del Sistema de Información Geográfica. Para la elaboración de las encuestas de aptitud, se utilizaron bases de datos públicas disponibles, principalmente de bases cartográficas e imágenes de satélite geo referenciadas. A partir de estos datos se elaboró una matriz, en la que se asignaron pesos a cada variable de acuerdo con la importancia y el tamaño de cada factor. La evaluación utilizó herramientas de análisis y cálculo multicriterio basadas en Sistemas de Información Geográfica, para obtener un mapa de aptitudes para la instalación de parques solares fotovoltaicos. La aptitud fue fuertemente influenciada por el potencial de radiación solar (GHI) y la proximidad a las líneas de transmisión. El análisis multicriterio fue efectivo para identificar las áreas con mayor potencial para la implementación de proyectos solares fotovoltaicos. Se observó que existe una influencia significativa de los pesos asignados y la diversidad en la resolución y el margen de error de los datos de entrada en el mapa obtenido. La inclusión de otras variables, una mejor calibración del peso y una mayor precisión de los datos georeferenciados son factores clave para obtener resultados más precisos.

Palabras clave: Energía solar fotovoltaica, Potencial de despliegue, Geoprocesamiento, Álgebra de mapas.

\section{INTRODUÇÃo}

0 consumo de combustíveis fósseis, a poluição do meio ambiente e a utilização de matrizes energéticas que promovem grandes impactos ambientais negativos são apontados como três fatores característicos do atual modelo de desenvolvimento da sociedade (LEONZIO, 2017).

Diante deste cenário, diversos pesquisadores têm concentrado seus esforços para propor mudanças nas formas convencionais de geração de energia e na busca por fontes alternativas, como as renováveis, que possuam uma relação de viabilidade econômica, equilíbrio ecológico e que permitam satisfazer o avanço tecnológico (AZEVED0; NASCIMENTO; SCHRAM, 2017).

Fontes renováveis de energia são todas as formas de aproveitamento energético que apresentam como base a utilização de forças e processos naturais, sem promover grandes danos ao meio ambiente e de forma que o recurso em questão seja capaz de ser reabastecido, em uma escala de tempo humano (CELESTINO; JULIÃ0, 2017). Nesse contexto, enquadram-se a energia solar, o calor geotermal, a energia eólica, a energia proveniente das marés, a energia vinculada aos recursos hídricos e as várias formas de aproveitamento energético através das biomassas. Todas as referidas fontes podem causar alterações ecológicas, a depender do local de exploração e da magnitude da mesma. Qualquer projeto de instalação para utilização de um determinado recurso energético deve ser acompanhado de estudos aprofundados, tomando como base não apenas os interesses econômicos, mas questões que envolvem a adequada escolha da área e os 
Avaliação de Aptidão Técnica e Socioambiental para Implantação de Parques Solarees Fotovoltaicos com Sistema de Informação Geográfica - SIG

impactos ambientais associados (AZEVED0; NASCIMENT0; SCHRAM, 2017; JUNQUEIRA; UTURBEY, 2017).

A instalação destes projetos tem-se utilizado da ciência cartográfica como uma ferramenta auxiliar na tomada de decisões sobre os locais mais adequados e consequentemente, a identificação de áreas com maior aproveitamento do recurso energético em questão (FERNANDES, 2015; SANTOS; ARAÚJ0, 2016; CELESTINO; JULIÃ0, 2017). Estes processos e metodologias envolvem técnicas de análise geoespacial, topografia do terreno, utilização de imagens de satélites, fotoidentificação, processamento em Sistema de Informação Geográfica (SIG) e mapeamento de sistemas (rodoviários, hídricos, etc.).

Grande parte dos recursos energéticos renováveis estão disponíveis em regiões pouco desenvolvidas, distantes dos grandes centros consumidores e sujeitas a restrições ambientais. Promover a implantação de empreendimentos renováveis pode alavancar o desenvolvimento socioeconômico destas regiões e reforçar o suprimento energético do país. 0 mapeamento destas áreas envolve o uso de uma variedade de fontes de dados e diversos critérios que contemplem variáveis técnicas e socioambientais relevantes, ponderadas conforme sua importância. Os critérios devem ser determinados por gestores, especialistas, partes interessadas e grupos de interesse, visando a melhor tomada de decisões. Estes dados são oriundos de diversas fontes e são usualmente combinados num Sistema de Informação Geográfica (JANKE, 2010).

A energia solar é uma fonte de energia inesgotável, tendo em vista a escala de tempo de vida do planeta Terra. Essa energia tem sido utilizada para suprir as demandas industriais e residenciais, através de aproveitamento térmico, e também para produção de energia elétrica (INPE, 2017). Destaca-se nos últimos anos o sistema fotovoltaico, processo de transformação da radiação solar em eletricidade de forma direta (ANEEL, 2008). A energia solar fotovoltaica desempenha um papel cada vez mais importante na geração de eletricidade no mundo. Sua expansão se deve à crescente competitividade econômica, aliada à redução de emissões de gases de efeito estufa e potencial utilização em locais remotos com geração distribuída (REN21, 2018).

No Brasil existe um grande potencial de implantação de geradores solares fotovoltaicos em estruturas metálicas sobre o solo, por conta das áreas de grande disponibilidade de radiação solar (INPE, 2017). Em 2017, o Brasil tornou-se o segundo país da América Latina, após o Chile, subindo para o décimo lugar no ranking mundial em 2017 (REN21, 2018). De acordo com a EPE (2012), além dos elevados níveis de insolação, o Brasil possui diversas reservas de quartzo de qualidade, as quais podem gerar competitividade no mercado com a produção de silício com 
alto grau de pureza, células e módulos solares, produtos de alto valor agregado. Desta forma, haveria maior atração dos investidores e desenvolvimento de um mercado interno, permitindo crescimento do papel da energia solar fotovoltaica na matriz elétrica brasileira.

0 processo de contratação de energia no Brasil tem sido adaptado à implantação de geração solar fotovoltaica centralizada. A partir de 2014, por meio de leilões específicos de aquisição de energia fotovoltaica, usinas de grande porte (centenas de MWp) vêm sendo contratadas em lotes que normalmente superam 1 GWp de potência (INPE, 2017).

Para desenvolver projetos de usinas fotovoltaicas centralizadas de grande porte é necessário avaliar o potencial energético solar da região, assim como procurar obter o maior aproveitamento da irradiação incidente por meio de mecanismos de rastreamento do Sol que movimentam o conjunto de painéis fotovoltaicos e podem ter um ou dois eixos de rotação. Concorrem ainda a escolha da tecnologia utilizada nos módulos fotovoltaicos e questões como proximidade de linhas de transmissão e interferência com acidentes do terreno como presença de municipalidades e estradas, entre outras (INPE, 2017).

Os sistemas com seguimento em um eixo (no sentido Leste-0este) são mais baratos e os mais utilizados no Brasil (INPE, 2017). No Leilão A-4 de 2018, 96\% dos projetos habilitados utilizaram esse tipo de estrutura, contra 97\% no leilão de 2017 (EPE, 2018).

Outro fato relevante que se verificou nos últimos dez anos está relacionado à redução de preços da tecnologia fotovoltaica, que por sua vez reflete em custos cada vez mais competitivos das usinas solares de grande porte em comparação com a geração convencional (INPE, 2017).

A variabilidade do recurso solar, bem como sua disponibilidade, está associada às condições de tempo e clima da localidade. Estas oscilações acontecem porque sistemas meteorológicos causam mudanças na nebulosidade e nas concentrações dos gases e aerossóis, afetando os processos radiativos que podem abrandar a radiação solar na atmosfera.

0 potencial de aproveitamento energético solar de uma determinada região é definido, principalmente, em função de sua localização no Globo Terrestre. As regiões localizadas entre as linhas tropicais podem ser encaradas como de potencial alto e as regiões localizadas entre os círculos polares e os trópicos podem ser encaradas como de potencial médio de energia solar (BIODINÂMICA, 2018). A escolha da melhor inclinação dos painéis solares depende da latitude e das condições climáticas (TELLO ORTIZ, 2014). Dependendo da localização e da tecnologia utilizada, os ganhos na geração de energia podem variar de 20\% a 50\% (TOLMASQUIM, 2016). 
0s levantamentos de dados de irradiação solar servem como base para a preparação de mapas de potencial de geração, tendo o Sol como fonte de energia. Segundo Tolmasquim (2016), o posicionamento geográfico do Brasil é favorável para 0 aproveitamento solar por possuir bons índices de irradiação solar em praticamente todo o território, inclusive em meses com baixa insolação.

Segundo a EPE (2018) para o uso fotovoltaico, deve-se considerar principalmente a Irradiação Global Horizontal (GHI), que é formada pela Irradiação Difusa Horizontal (DHI) e pela Irradiação Direta Normal (DNI). Em dias nublados, a principal componente é a DHI (parcela dispersa e atenuada por reflexões), enquanto nos dias claros, prevalece a DNI (parcela que chega à superfície sem desvios).

A irradiância solar é uma unidade de densidade de potência, usualmente expressa em $\mathrm{W} / \mathrm{m}^{2}$ ou $\mathrm{kW} / \mathrm{m}^{2}$ e a irradiação solar é uma unidade de densidade de energia, usualmente expressa em $\mathrm{kWh} / \mathrm{m}^{2}$ dia ou $\mathrm{kWh} / \mathrm{m}^{2}$ ano.

A radiação solar incidente na superfície terrestre pode ser medida através de estações meteorológicas, por satélites meteorológicos ou estimada através de modelos solares gerados a partir de SIG.

Apesar de ser possível medir a radiação solar global diretamente no local, por meio de torres/estações solarimétricas, essa alternativa nem sempre é viável por conta do alto custo com equipamentos e ao acesso restrito à alguns pontos de medição. Dentre os modelos desenvolvidos para estimativa de radiação solar destacam-se aqueles baseados principalmente em temperatura e insolação, que necessitam de monitoramento em campo para calibração dos equipamentos.

Nesse sentido o geoprocessamento encontra-se como um método alternativo para a estimativa de radiação solar incidente em um determinado local. Permite gerar informações adequadas para a tomada de decisão, uma vez que se baseia em tecnologias de custo baixo quando comparado com a aquisição de dados locais (CÂMARA; DAVIS, 2004).

0 SIG foi utilizado neste estudo com a intenção de trabalhar com um só programa, o ArcGIS, e que os dados fossem de acesso livre. Em experiência profissional esses dados são obtidos por estações meteorológicas privadas, as quais são instaladas pelas empresas para fins de constatação do potencial solar à Empresa de Pesquisa Energética. Esses dados não se tornam públicos de tal forma que não é possível utilizá-los. 
Além disso, alguns estudos consideram a utilização de imagens de satélite para a obtenção de estimativa de radiação solar (KAURIA, 2016; LIMA; BISP0; RIFFEL, 2016; G0MES et al., 2019; MARTINI, 2019).

0 termo geoprocessamento surgiu com a introdução dos conceitos de manipulação de dados espaciais georreferenciados em sistemas computadorizados, através das ferramentas denominadas Sistemas de Informações Geográficas - SIG (CÂMARA; ORTIZ, 1998).

0 uso do SIG é cada vez mais necessário na análise do espaço geográfico, principalmente nas áreas onde o volume de dados manipulados é muito grande. As geotecnologias auxiliam também na definição das áreas de influência em um projeto. As equipes multidisciplinares avaliam o contexto geográfico da região na qual será instalado o empreendimento e partir de discussões e análise de dados, são definidas as áreas de influência direta e indireta dos meios físico, biótico e socioeconômico.

A avaliação da aptidão ou viabilidade de uma área para a instalação de qualquer empreendimento se baseia na agregação de diversos dados espaciais de diferentes fontes, de forma a gerar um resultado combinado. Uma das melhores opções para realizar a combinação significativa desses dados de critérios definidos pelo usuário é o uso dos SIG (JANKE, 2010).

Nas estimativas de potencial solar para os municípios de Melbourne (COOPER; ROBERTS; BRUCE, 2018a) e Adelaide (COOPER; ROBERTS; BRUCE, 2018b), ambos na Austrália, foram utilizados dados da banda do infravermelho próximo (IV) emitidos e captados pelo sensor LiDAR (Light Detection and Ranging) para geração de modelo digital de elevação e características topográficas, que foram aplicados à estimativa do potencial fotovoltaico de coberturas construídas.

Para a área total da Croácia, Gasparovic et al. (2019) analisaram a distribuição do potencial solar a partir de diferentes fontes de dados, entre esses a $\mathrm{GHI}$ processada no módulo r.sun do SIG livre QGIS, e compararam com dados obtidos por estações meteorológicas.

Apesar da complexidade na estimativa e comparação do potencial solar em estudos, não é comum a consideração de outros fatores para a indicação de locais mais aptos para a instalação de painéis ou usinas fotovoltaicas.

No estudo sobre potencial solar no Sudão (BABIKER, 2020) como alternativa a geração de energia por biomassa, foram indicadas outras questões que devem ser consideradas para 0 aproveitamento da energia solar em placas fotovoltaicas, como o nível de poluição atmosférica, que influencia na incidência de raios solares. 
A definição das variáveis a serem utilizadas na realização de uma avaliação da aptidão de um local para a instalação de parques de geração de energia solar fotovoltaica sobre o solo é uma etapa preliminar de projeto. Este processo de definição depende da opinião dos diversos profissionais envolvidos no projeto. As singularidades de cada região avaliada, além das legislações vigentes e do nível de detalhamento que se deseja obter nesta investigação são fatores que implicam na multidisciplinaridade.

No Relatório Ambiental Simplificado realizado no processo do licenciamento da Usina Fotovoltaica (UFV) Bonito (CARUSO JR., 2018), de maneira geral, foram avaliadas diferentes áreas a fim de obter a melhor solução de localização para implantação da usina fotovoltaica, segundo os critérios de: incidência de radiação solar com a intensidade e constância exigida; proximidade à subestação onde haverá a conexão e o posterior escoamento de energia; disponibilidade de propriedades aptas ao arrendamento; delimitação das áreas de restrição ambiental; e infraestrutura da região.

Na análise das alternativas locacionais realizada no âmbito do Estudo de Impacto Ambiental para o Complexo Eólico-Solar Serra da Babilônia (BIODINÂMICA, 2018) alguns fatores físicos, bióticos e socioeconômicos foram considerados como restrições ambientais.

0 levantamento de potencial para a instalação, em uma determinada região, de qualquer empreendimento que considere diversos fatores requer a utilização de algum método que realize a combinação dos critérios avaliados. Nesse contexto, a análise multicritério é um conjunto de procedimentos ou regras que envolvem a utilização de dados espaciais em conjunto com definições estabelecidas pelo tomador de decisão para gerar um resultado, o qual geralmente é um mapa (MALCZEWSKI, 2004).

0 desafio consiste em encontrar uma solução que vá de encontro ao objetivo inicial da análise sem comprometer ou com o mínimo de efeitos ou impactos sobre áreas em que os usos possam ser contraditórios.

No caso da aptidão de áreas para instalação de parques solares fotovoltaicos, os critérios que vão classificar esta aptidão devem priorizar os objetivos estabelecidos e a tentativa de redução dos conflitos entre eles, resultando numa solução apropriada (CARRIÓN et al., 2008; EASTMAN, 2012).

A análise multicritério permite integrar diversas variáveis em um SIG, sendo utilizada na procura da localização ideal para uma intervenção no ambiente (KALE et al., 2005; CARRIÓN et al., 2008). 
Os SIG fornecem os meios para gerir a informação que descreve o território e implementar os critérios definidos. A análise multicritério fornece as técnicas que permitem a agregação dos critérios de acordo com a metodologia selecionada de forma a obter o resultado da aptidão e assim, escolher as opções mais adequadas (JOERIN et al., 2001).

A aptidão de determinado território para determinado uso é dada em função da conjugação entre fatores relacionados com as características intrínsecas deste território e com suas potencialidades (CAMP0 et al., 2004). Para avaliar a aptidão territorial relativa a determinada temática pressupõe, por um lado, a existência de uma grande variedade de dados que caracterizem e representem geográfica e fisicamente o território e a temática, e por outro lado, a definição e identificação dos pesos ou ponderações a atribuir a cada um dos dados de entrada no modelo (JANKE, 2010).

Embora existam muitas técnicas, “o método para a definição dos pesos dos critérios não é consensual e a quantificação de importância relativa de cada critério constitui uma das grandes dificuldades encontradas num processo de decisão que envolve a análise multicritério” (CABRAL, 2012).

\section{MATERIAL E MÉTODOS}

A metodologia utilizada neste trabalho busca demonstrar a utilidade do SIG na prospecção de áreas para instalação de parques solares. Buscou-se contemplar uma microrregião que não apresenta parques solares instalados.

Foram estimadas as áreas potenciais para instalação de usina solar fotovoltaica na microrregião Campo Maior, no Estado do Piauí.

0 estudo considera que as melhores alternativas de localização de uma UFV são obtidas não somente através do potencial solar, mas também quando se observa os componentes ambientais, ou seja, quando a escolha considera a menor intervenção socioambiental possível, causando assim menos impacto ambiental negativo.

Cabe ressaltar que este estudo não contemplou o projeto técnico da usina (potência, tipo de placa solar, área de implantação em ha/MW, custos, margem de escoamento da NOS, entre outros). Foi estimado somente as áreas que possuem potencial para tal geração.

Para estimar a irradiação solar desta microrregião foi gerado um Modelo Digital de Elevação com imagens da Missão Topográfica de Radar Embarcado (SRTM), que foi utilizado 
Avaliação de Aptidão Técnica e Socioambiental para Implantação de Parques Solarees Fotovoltaicos com Sistema de Informação Geográfica - SIG

para estimar a irradiação pela ferramenta Area Solar Radiation, no software ArcGIS 10.3, licença GISCursos.

A irradiação foi reclassificada para gerar o potencial solar. Posteriormente, este foi integrado a fatores ambientais em ferramenta de álgebra de mapas no software ArcGIS 10.3, licença GISCursos, para estimar a aptidão para implementação de usina solar fotovoltaica.

A avaliação consistiu na análise espacial dos parâmetros pré-definidos (fatores ambientais), como apresentados no Quadro 1, de modo que ao final do processamento dos dados foi determinado um índice de aptidão ambiental para instalação do empreendimento.

A área escolhida para a aplicação desta metodologia foi a Microrregião Campo Maior, localizada no Estado do Piauí (Figura 1).

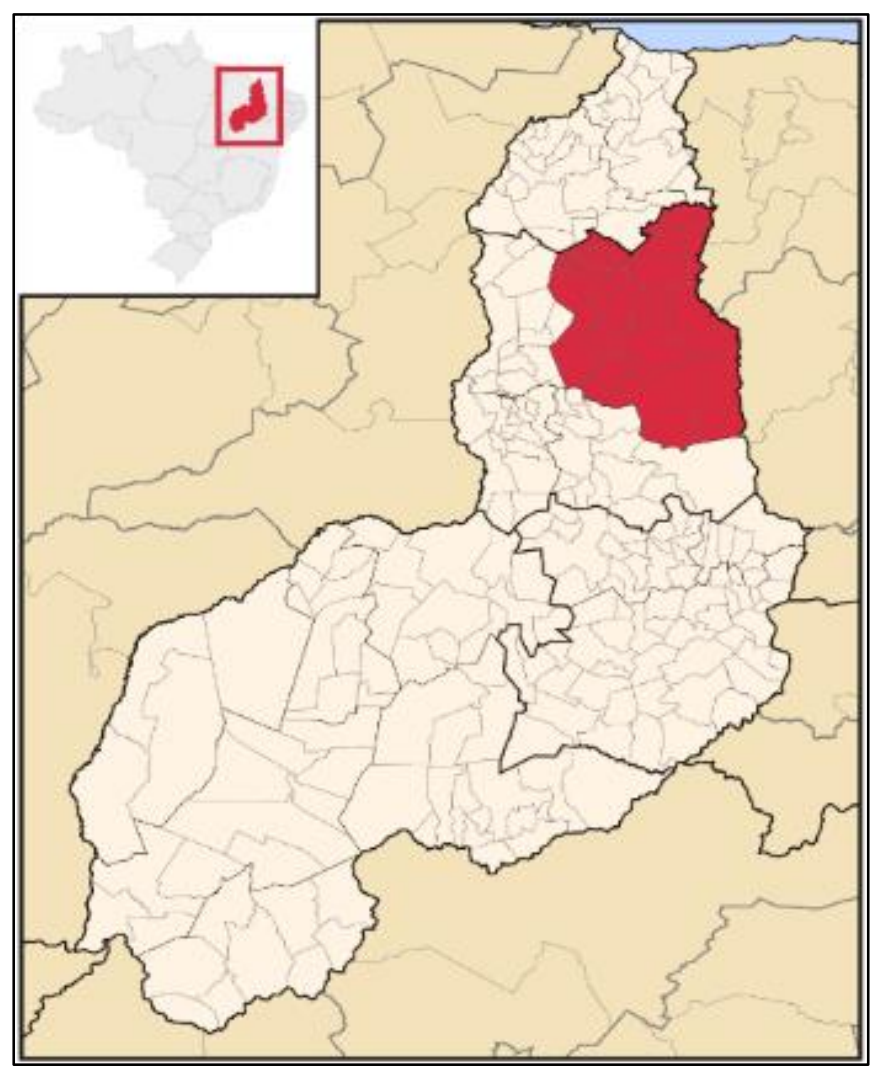

Figura 1 - Localização da Microrregião Campo Maior.

Fonte: Escolano, 2019.

Ressalta-se que nesta localidade não há registros de parques solares fotovoltaicos previamente instalados, conforme o Sistema de Informações Georreferenciadas do Setor Elétrico (ANEEL, 2019). Desta forma, o estudo a respeito da aptidão da microrregião Campo Maior poderá auxiliar os estudos de viabilidade deste tipo de empreendimento. Ainda, o conhecimento sobre a área de estudo foi considerado na definição da área de estudo. 
As variáveis consideradas neste estudo foram definidas com base na sua relevância e limitações no processo de licenciamento e de implantação de empreendimentos de geração de energia de fonte solar e similares.

Os parâmetros examinados foram: irradiação solar; presença de territórios indígenas; processos minerários; presença de territórios remanescentes de quilombolas; presença de sítios arqueológicos; presença de cavidades naturais subterrâneas (cavernas); interferência em Reservas Legais; assentamentos rurais; interferência em Unidades de Conservação; Linhas de Transmissão e Subestações; proximidade de rodovias e estradas; declividade do terreno; interferência em Área de Preservação Permanente (APP); interferência em corpos hídricos; e uso e ocupação do solo.

Para a avaliação das áreas de menor impacto socioambiental e das áreas com infraestrutura utilizou-se uma matriz, na qual foram atribuídos valores para cada variável de acordo com a importância e dimensão de cada fator apresentado. Os menores valores indicam que há mais restrições e menor aptidão da área, enquanto os maiores valores indicam menor restrição e, portanto, indica áreas mais aptas. Entretanto, esta avaliação é considerada a partir de critérios de macrolocalização, com base, sobretudo em dados secundários, o que pode ser alterado, quando da definição exata de localização da UFV (ECOLOGY BRASIL, 2018).

Como os critérios avaliados apresentam importâncias diferenciadas, o respectivo peso do impacto associado é diferente para cada componente ambiental de acordo com a sua importância e influência na aptidão de uma área para a instalação de UFV. Foram adotados pesos de 1 a 4 , sendo 1 para menor e 4 para maior importância do critério, levando em conta a legislação ambiental pertinente à localidade, com pontos e pesos (Quadro 1).

Cabe ressaltar que esta metodologia não se limita aos parâmetros aqui considerados, sendo possível aprimorar este ensaio com outras variáveis, tais como quantidade de população atendida e custo da instalação.

A atribuição de valores para as áreas protegidas foi adotada ao invés da exclusão destas áreas para análise, a fim de permitir a avaliação de potencial solar que pode ser aplicado a projetos integrados com as comunidades tradicionais ou com as práticas conservacionistas das áreas naturais protegidas.

Quadro 1 - Pontuação e peso de cada parâmetro avaliado.

\begin{tabular}{|c|c|c|}
\hline Parâmetros & Pontuação & Peso \\
\hline
\end{tabular}


Avaliação de Aptidão Técnica e Socioambiental para Implantação de Parques Solarees Fotovoltaicos com Sistema de Informação Geográfica - SIG

\begin{tabular}{|c|c|c|c|c|c|}
\hline & $\begin{array}{l}0 \text { (menos } \\
\text { favorável) }\end{array}$ & 1 & 2 & $\begin{array}{c}3 \text { (mais } \\
\text { favorável) }\end{array}$ & 2 \\
\hline Potencial solar & $\begin{array}{c}\text { Menor que 5,17 } \\
\mathrm{kWh} / \mathrm{m}^{2} \text {.dia }\end{array}$ & - & $\begin{array}{c}\text { Entre } 5,17 \text { e } 5,23 \\
\text { kWh } / \mathrm{m}^{2} \text {.dia }\end{array}$ & $\begin{array}{c}\text { Maior que 5,23 } \\
\mathrm{kWh} / \mathrm{m}^{2} . \text { dia }\end{array}$ & 2 \\
\hline $\begin{array}{c}\text { Linhas de } \\
\text { transmissão e } \\
\text { subestações }\end{array}$ & $\begin{array}{c}\text { Distância maior } \\
\text { que } 60 \mathrm{~km}\end{array}$ & $\begin{array}{l}\text { Distância entre } \\
40 \text { e } 60 \mathrm{~km}\end{array}$ & $\begin{array}{c}\text { Distância entre } 20 \\
\text { e } 40 \mathrm{~km}\end{array}$ & $\begin{array}{c}\text { Distância menor } \\
\text { que } 20 \text { km }\end{array}$ & 1 \\
\hline $\begin{array}{l}\text { Declividade do } \\
\text { terreno }\end{array}$ & $\begin{array}{c}\text { Muito alta } \\
\text { declividade (> 17\%) }\end{array}$ & $\begin{array}{l}\text { Alta declividade } \\
\quad(12 \text { a } 17 \%)\end{array}$ & $\begin{array}{l}\text { Média declividade } \\
\quad(6 \text { a } 12 \%)\end{array}$ & $\begin{array}{c}\text { Baixa declividade } \\
\quad(0 \text { a } 6 \%)\end{array}$ & 1 \\
\hline $\begin{array}{l}\text { Territórios } \\
\text { indígenas }\end{array}$ & $\begin{array}{c}\text { Presença de } \\
\text { território indigena }\end{array}$ & - & $\begin{array}{l}\text { Faixa de } 8 \mathrm{~km} \mathrm{de} \\
\text { distância de } \\
\text { território indígena }\end{array}$ & $\begin{array}{l}\text { Ausência de } \\
\text { território indigena }\end{array}$ & 1 \\
\hline $\begin{array}{l}\text { Processos } \\
\text { minerários }\end{array}$ & $\begin{array}{c}\text { Presença de } \\
\text { processos } \\
\text { minerários em } \\
\text { exploração }\end{array}$ & - & $\begin{array}{c}\text { Presença de } \\
\text { processos } \\
\text { minerários em } \\
\text { pesquisa }\end{array}$ & $\begin{array}{l}\text { Ausência de } \\
\text { processos } \\
\text { minerários }\end{array}$ & 1 \\
\hline $\begin{array}{l}\text { Comunidades } \\
\text { Quilombolas }\end{array}$ & $\begin{array}{c}\text { Presença de } \\
\text { comunidade } \\
\text { quilombola }\end{array}$ & - & $\begin{array}{c}\text { Faixa de } 8 \mathrm{~km} \text { de } \\
\text { distância de } \\
\text { comunidade } \\
\text { quilombola }\end{array}$ & $\begin{array}{c}\text { Ausência de } \\
\text { comunidade } \\
\text { quilombola }\end{array}$ & 1 \\
\hline $\begin{array}{c}\text { Sítios } \\
\text { arqueológicos }\end{array}$ & $\begin{array}{l}\text { Presença de sítios } \\
\text { arqueológicos } \\
\text { (buffer de } 500 \mathrm{~m} \text { a } \\
\text { partir do sítio) }\end{array}$ & - & - & $\begin{array}{l}\text { Ausência de sitios } \\
\text { arqueológicos }\end{array}$ & 1 \\
\hline $\begin{array}{l}\text { Registro de } \\
\text { Cavernas }\end{array}$ & $\begin{array}{c}\text { Presença de } \\
\text { cavidades (buffer } \\
\text { de } 500 \text { m a partir } \\
\text { da cavidade) }\end{array}$ & - & - & $\begin{array}{c}\text { Ausência de } \\
\text { cavidades }\end{array}$ & 1 \\
\hline Reservas Legais & Com interferência & - & - & Sem interferência & 1 \\
\hline $\begin{array}{c}\text { Assentamentos } \\
\text { rurais }\end{array}$ & $\begin{array}{c}\text { Presença de } \\
\text { projetos de } \\
\text { assentamentos } \\
\text { (buffer de } 2,5 \mathrm{~km} \text { ) }\end{array}$ & - & - & $\begin{array}{c}\text { Ausência de } \\
\text { projetos de } \\
\text { assentamentos }\end{array}$ & 1 \\
\hline $\begin{array}{c}\text { Unidades de } \\
\text { Conservação (UC) }\end{array}$ & $\begin{array}{c}\text { Presença de } \\
\text { unidade de } \\
\text { conservação de } \\
\text { proteção integral }\end{array}$ & $\begin{array}{c}\text { Presença de } \\
\text { unidade de } \\
\text { conservação de } \\
\text { uso sustentável }\end{array}$ & $\begin{array}{c}\text { Zona de } \\
\text { Amortecimento } \\
\text { (ZA) ou faixa de } \\
\text { entorno de } 5 \mathrm{~km} \\
\text { de distância de UC } \\
\text { sem ZA } \\
\text { estabelecida }\end{array}$ & $\begin{array}{l}\text { Ausência de } \\
\text { unidade de } \\
\text { conservação }\end{array}$ & 1 \\
\hline $\begin{array}{l}\text { Rodovias e } \\
\text { Estradas }\end{array}$ & $\begin{array}{c}\text { Presença de } \\
\text { estradas e acessos } \\
\text { a mais de } 10 \mathrm{~km}\end{array}$ & $\begin{array}{c}\text { Presença de } \\
\text { estradas e } \\
\text { acessos a } \\
\text { menos de } 10 \mathrm{~km}\end{array}$ & $\begin{array}{c}\text { Presença de } \\
\text { estradas e acessos } \\
\text { a menos de } 5 \mathrm{~km}\end{array}$ & $\begin{array}{c}\text { Presença de } \\
\text { estradas e acessos } \\
\text { a menos de } 1 \mathrm{~km}\end{array}$ & 1 \\
\hline $\begin{array}{c}\text { Áreas de } \\
\text { Preservação } \\
\text { Permanente } \\
\text { (APP) }\end{array}$ & Presença de APP & - & - & Ausência de APP & 1 \\
\hline
\end{tabular}




\begin{tabular}{|c|c|c|c|c|c|}
\hline $\begin{array}{c}\text { Interferências } \\
\text { em corpos } \\
\text { hídricos }\end{array}$ & $\begin{array}{c}\text { Presença de corpos } \\
\text { d'água }\end{array}$ & - & - & $\begin{array}{c}\text { Ausência de } \\
\text { interferência em } \\
\text { corpos d'água }\end{array}$ & 1 \\
\hline Uso e ocupação \\
do solo & $\begin{array}{c}\text { Vegetação arbórea, } \\
\text { área urbanizada, } \\
\text { povoamento e } \\
\text { intervenção em } \\
\text { corpos d'água }\end{array}$ & $\begin{array}{c}\text { Vegetação } \\
\text { herbácea e } \\
\text { arbustiva } \\
\text { nativas }\end{array}$ & $\begin{array}{c}\text { Áreas } \\
\text { antropizadas, } \\
\text { pastagem e } \\
\text { culturas }\end{array}$ & Sem intervenção & 1 \\
\hline
\end{tabular}

Fonte: Escolano, 2019.

A integração das camadas com pesos e valores foi realizada com soma ponderada na ferramenta Weighted Sum do ArcGIS 10.3 (FISHBURN, 1967), que demanda dados expressos da mesma unidade de medida ou valor.

\section{RESULTADOS E DISCUSSÃ0}

Foram geradas imagens (Figuras 2 a 4) e um mapa de aptidão para a instalação de parques solares fotovoltaicos (Figura 6).

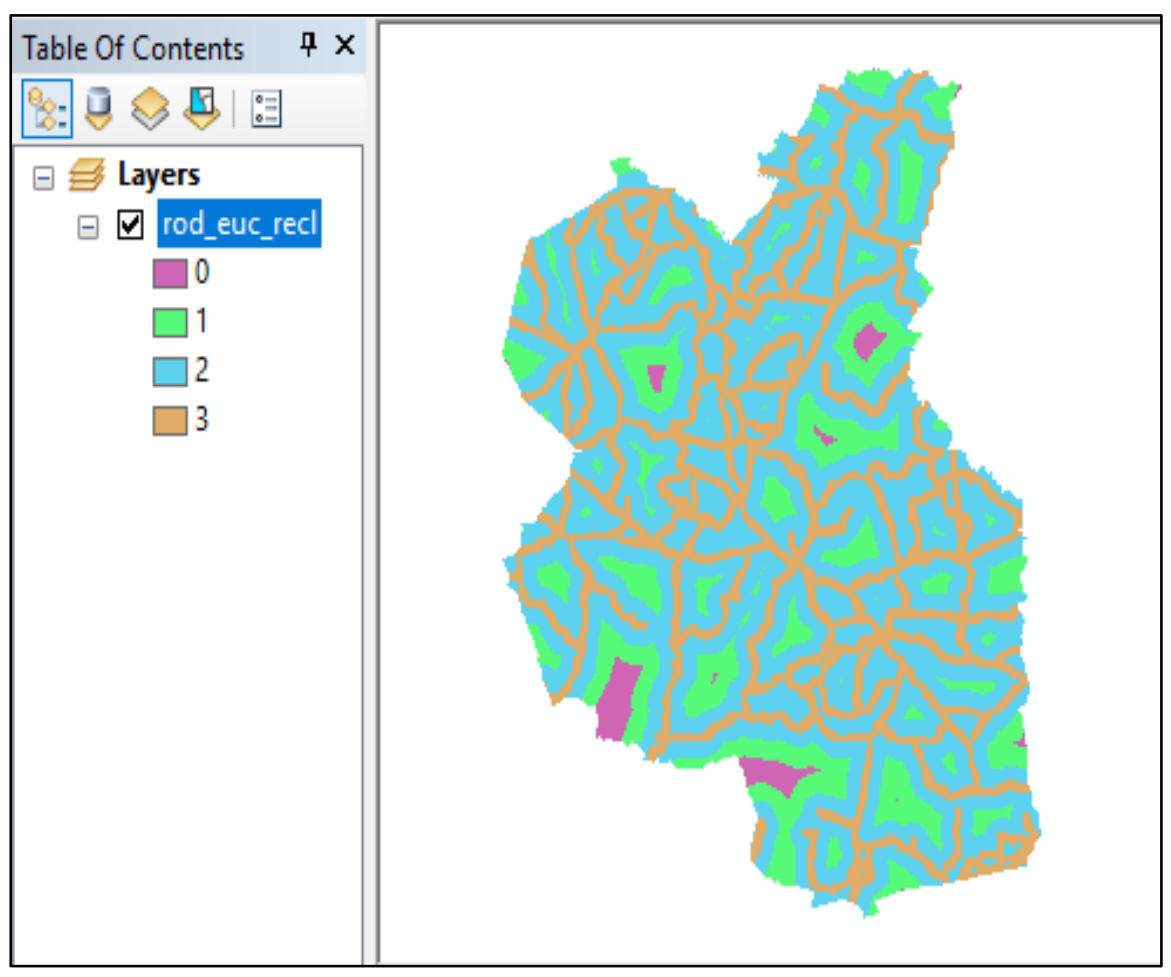

Figura 2 - Imagem de rodovias e estradas.

Fonte: Escolano, 2019. 
Avaliação de Aptidão Técnica e Socioambiental para Implantação de Parques Solarees Fotovoltaicos com Sistema de Informação Geográfica - SIG

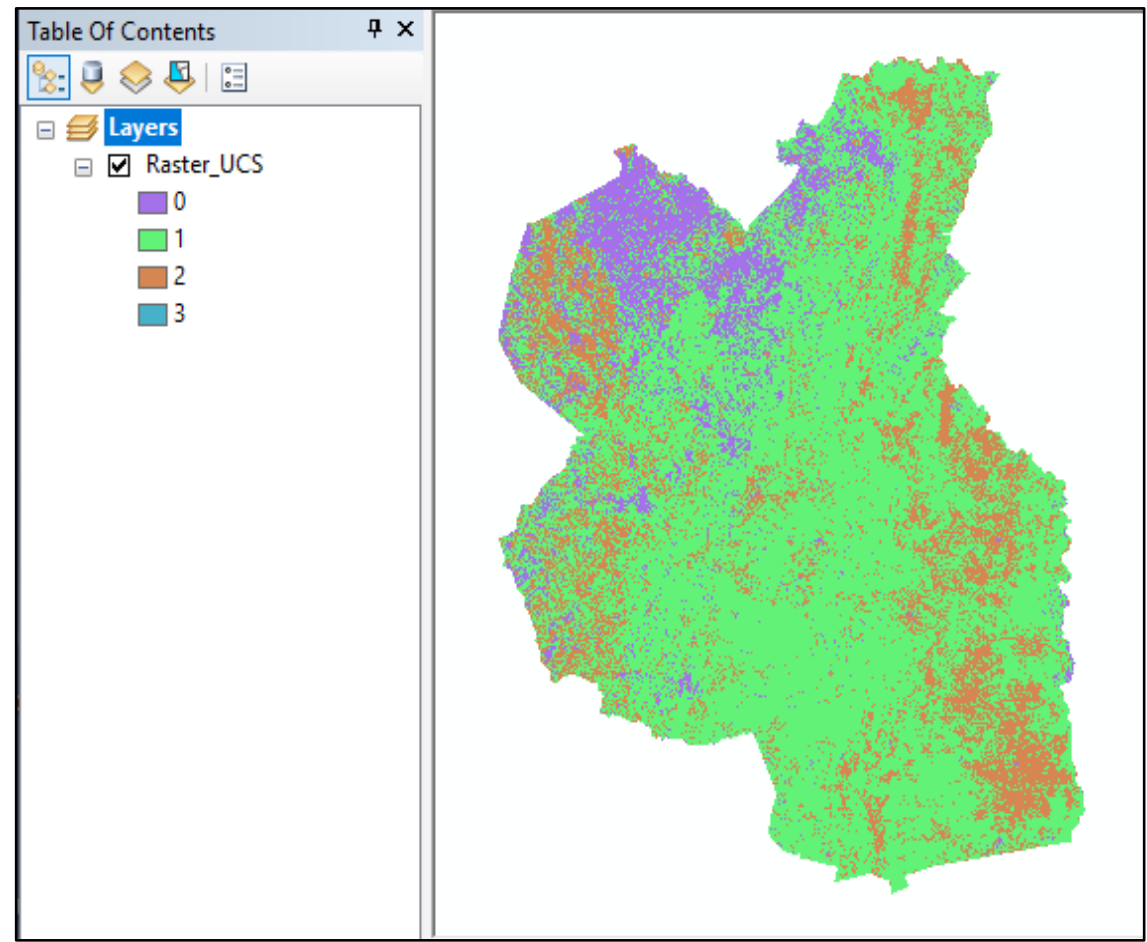

Figura 3 - Imagem de uso e ocupação do solo.

Fonte: Escolano, 2019.

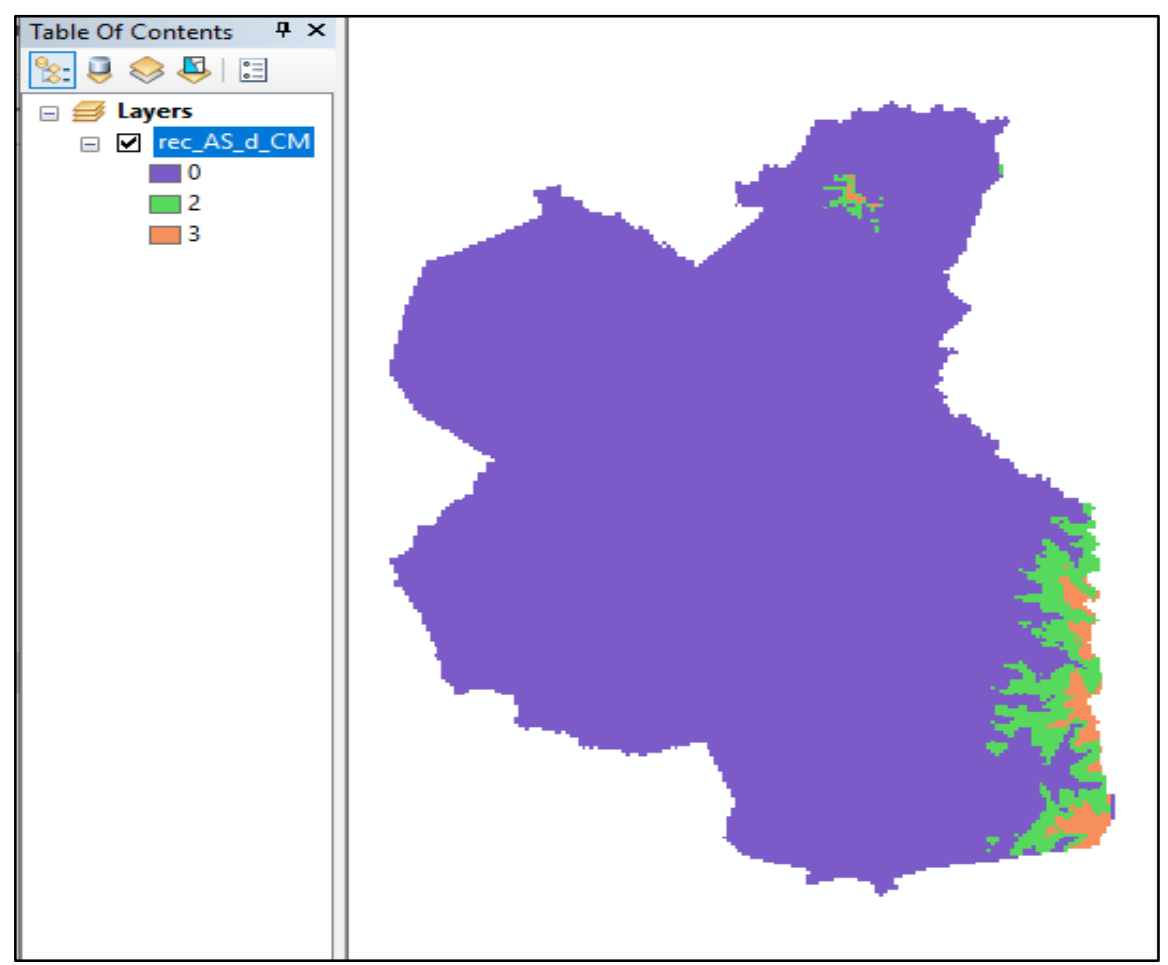

Figura 4 - Imagem do potencial solar.

Fonte: Escolano, 2019.

0 resultado obtido apresentou maior aptidão para as regiões sudeste e noroeste da microrregião (Figuras 5 e 6). Ressalta-se que a aptidão da região sudeste converge com a área 
que possui grande potencial de irradiação solar e a região noroeste converge com a área próxima das linhas de transmissão.

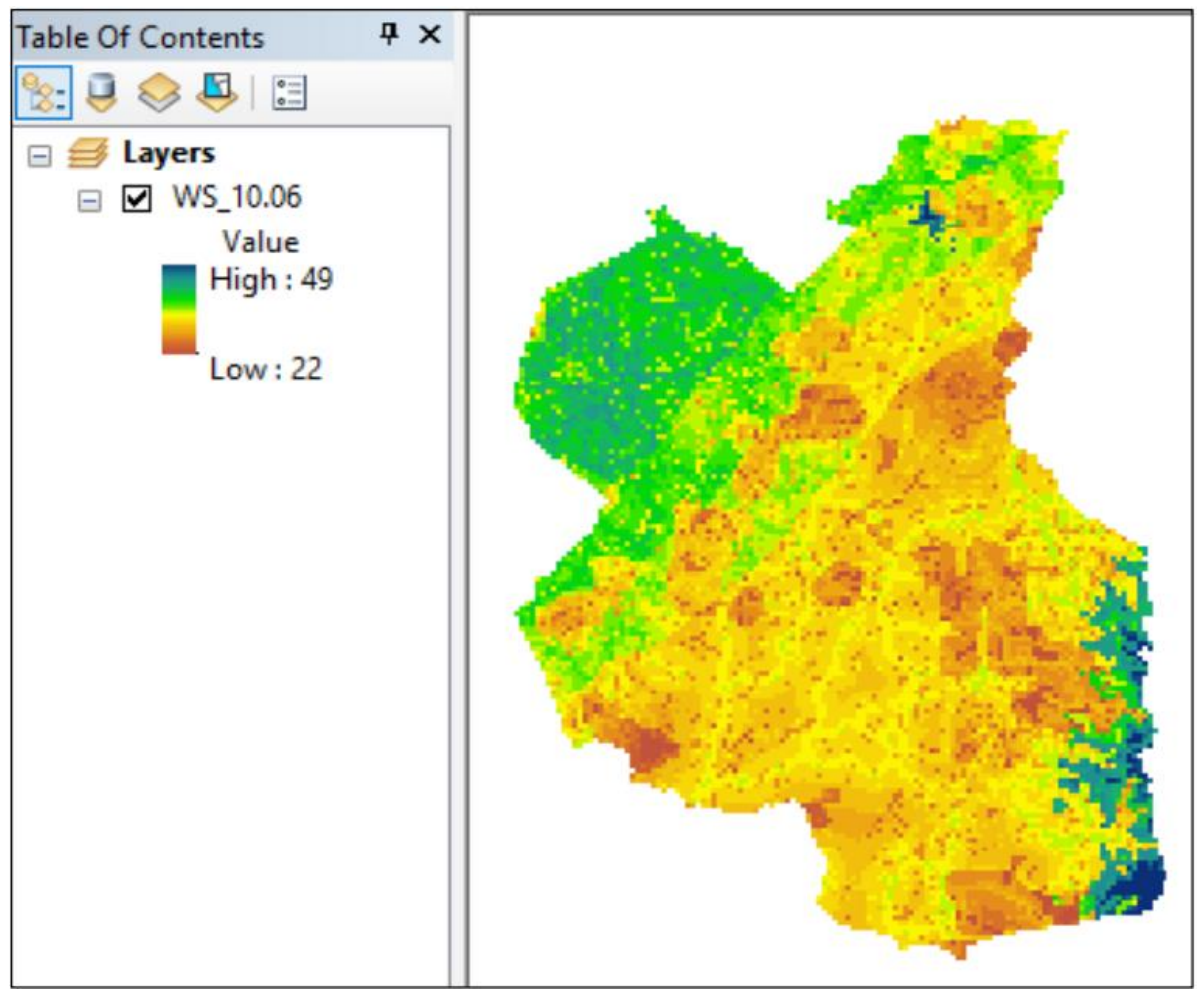

Figura 5 - Imagem do resultado da ferramenta Weighted Sum. Fonte: Escolano, 2019.

Além disso, a partir do cálculo da área de cada polígono presente no mapeamento final de aptidão e do seu respectivo cruzamento com o mapa de potencial solar foi possível obter a relação entre áreas para a instalação de empreendimentos solares fotovoltaicos (Quadro 2). Como o potencial solar foi o fator que recebeu o maior peso, é possível observar que 95,5\% que foram classificadas com grande potencial solar coincidem com os locais identificados com alta aptidão. Entretanto, verifica-se que $70 \%$ da área considerada de alta aptidão possui baixo potencial solar. Isto se deve ao fato da variável Linhas de Transmissão e Subestações ter recebido peso relativamente grande em comparação às demais variáveis.

As áreas de menor aptidão estão representadas numa escala de marrom, as aptidões moderadas numa escala de verdes e as melhores aptidões numa escala de azuis. Posteriormente, foi gerado um shapefile das áreas mais aptas.

A comparação entre as áreas de maior aptidão com os parâmetros foi acompanhada de visualização com sobreposição no Google Earth Pro. 


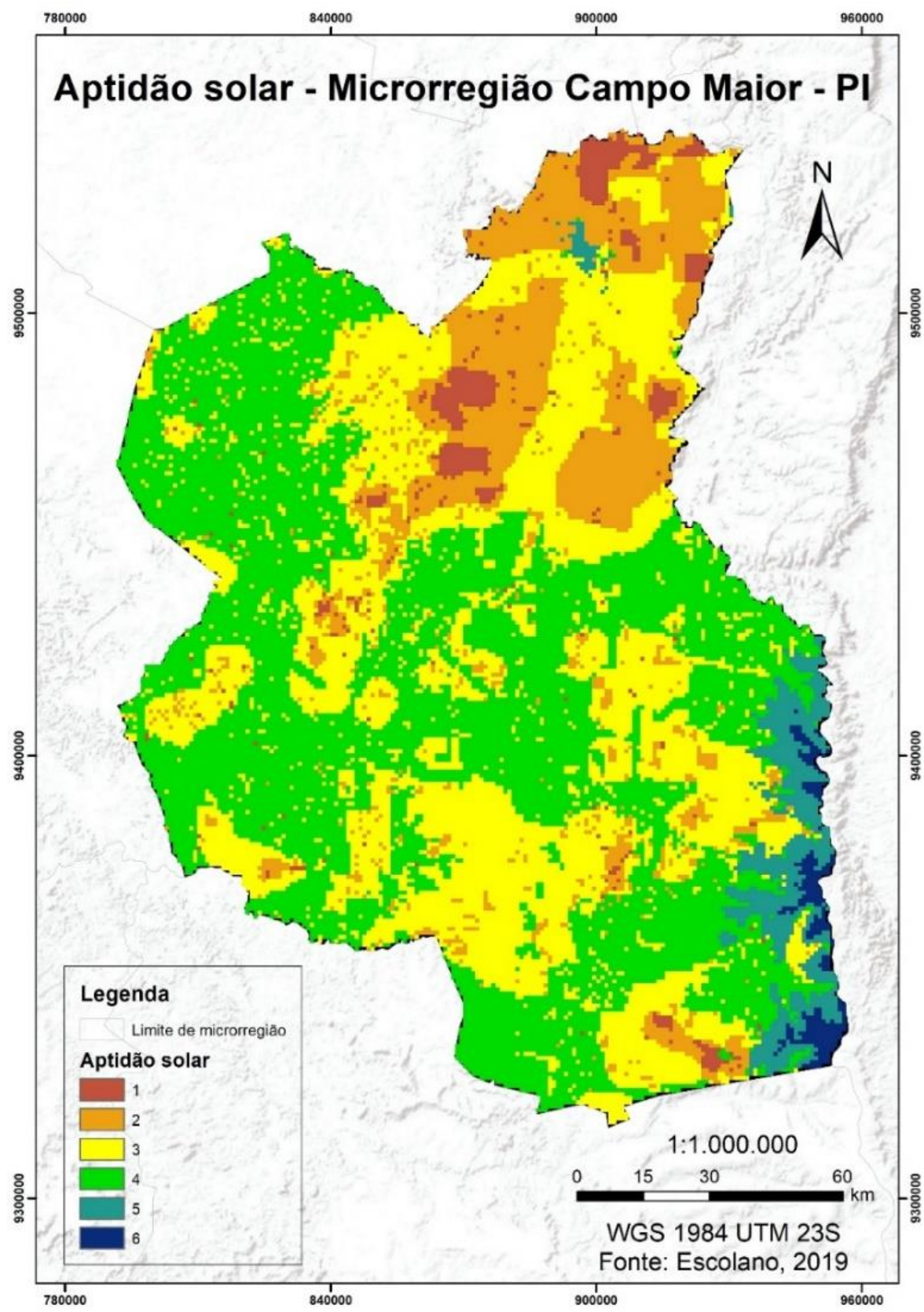

Figura 6 - Mapa da aptidão reclassificada em 6 intervalos iguais.

Fonte: Escolano, 2019.

Quadro 2 - Comparação entre aptidão e potencial solar.

\begin{tabular}{|c|c|c|c|c|}
\hline \multirow{3}{*}{ Aptidão } & Potencial Solar & $\begin{array}{c}\text { Área do Potencial } \\
\text { Solar (ha) }\end{array}$ & $\begin{array}{c}\text { Representatividade } \\
\text { em porcentagem }\end{array}$ & Área total (ha) \\
\hline \multirow{3}{*}{ Alta } & Alto & 144326 & 14 & \multirow{2}{*}{1017887} \\
\cline { 2 - 4 } & Médio & 160550 & 16 & \\
\cline { 2 - 5 } & Baixo & 713011 & 70 & 2441374 \\
\hline Média & Alto & 6422 & 0 & \\
\hline
\end{tabular}




\begin{tabular}{|c|c|c|c|c|}
\hline & Médio & 436696 & 18 & \\
\hline & Baixo & 1998256 & 82 & \\
\hline \multirow{3}{*}{ Baixa } & Alto & 338 & 0 & \multirow{3}{*}{669916} \\
\hline & Médio & 113399 & 17 & \\
\hline & Baixo & 556179 & 83 & \\
\hline
\end{tabular}

Fonte: Escolano, 2019.

A aplicação do modelo ao caso da Microrregião Campo Maior indicou aptidão para projetos solares fotovoltaicos, embora apresente poucas linhas de transmissão e subestações próximas para o escoamento da energia (Figura 7).

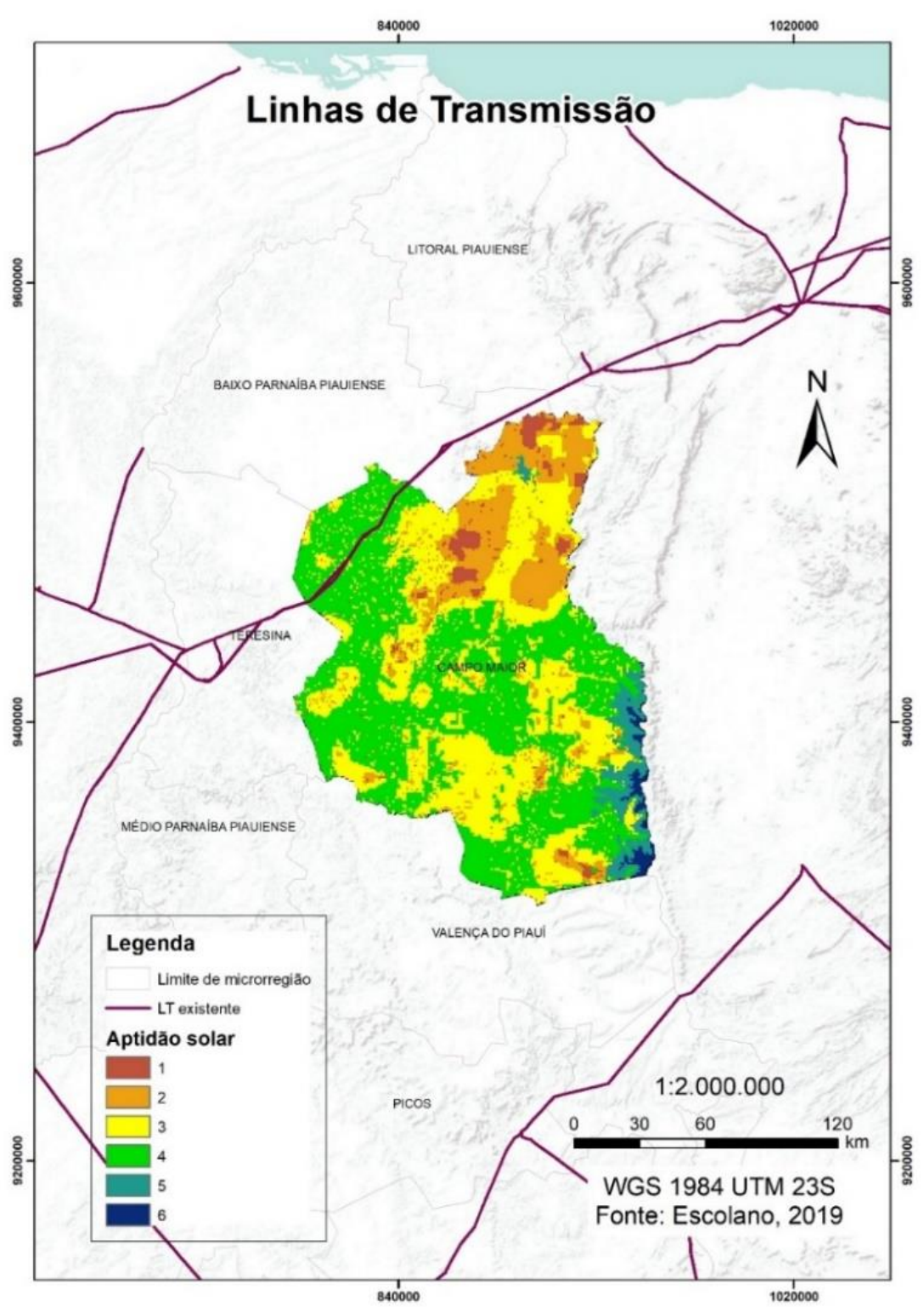

Figura 7 - Mapa das Linhas de Transmissão próximas à microrregião.

Fonte: Escolano, 2019. 
Ressalta-se que a linha de transmissão que parece cruzar a microrregião ainda está em fase de implantação, uma vez que foi objeto do leilão de transmissão de 15/12/2017, e desde então passou a ser de responsabilidade da empresa Serra de Ibiapaba Transmissora de Energia S.A. (EPE, 2018).

A álgebra de mapas permitiu indicar áreas mais aptas a partir dos parâmetros considerados. A validação deste processo se deu por sobreposição às imagens do software Google Earth Pro. A interceptação de áreas de alta aptidão com centros urbanos indicou imprecisão da base de dados de uso e ocupação de solo. Ainda, corpos d'água visíveis em imagens no Google Earth Pro não constavam na base de dados deste estudo, gerando imprecisão nas áreas compreendidas pelos buffers de APP.

\section{CONCLUSÃO}

A análise multicritério se mostrou eficaz na identificação das áreas com maior potencial para implantação de empreendimentos solares fotovoltaicos. Foi encontrado potencial alto em cerca de 24,6\% do território da microrregião Campo Maior. Isso se deve ao fato de que os locais com maior potencial de geração energética apresentaram aptidão para a instalação de parques, considerando os fatores avaliados. 0 estudo conseguiu identificar áreas com elevado potencial para implantação que ainda não foram consideradas nos projetos em planejamento de empreendimentos solares, uma vez que não existem empreendimentos na microrregião.

Acredita-se que a análise serviu para identificar as áreas com maior potencial para implantação de empreendimentos solares, mas não dispensa um estudo minucioso da área de instalação. 0 resultado pode ser mais detalhado com o uso de outros dados e que tenham maior resolução e menores erros, principalmente os de potencial solar, que devem ser validados ou corrigidos com dados obtidos por medições locais por meio de torres solarimétricas, que demandam um método experimental com custo que deve ser considerado.

Futuros projetos desta natureza podem incluir critérios que permitam a avaliação da aptidão numa escala mais ampla e abrangente, como incluindo critérios de caráter tecnológico (tipo de tecnologia e suas características) e econômico (potencial de produção, custo dos terrenos arrendados, entre outros).

\section{REFERÊNCIAS BIBLIOGRÁFICAS}

AGÊNCIA NACIONAL DE ENERGIA ELÉTRICA. Atlas de energia elétrica do Brasil. 3. ed. Brasília: ANEEL, 2008, 236 p. 
AGÊNCIA NACIONAL DE ENERGIA ELÉTRICA. Banco de Informações de Geração. Capacidade de Geração do Brasil. Disponível em: <http://www2.aneel.gov.br/aplicacoes/capacidadebrasil/capacidadebrasil.cfm>. Acesso em: 23 jun. 2019 .

AGÊNCIA NACIONAL DE ENERGIA ELÉTRICA. SIGEL. Disponível em: 〈https://sigel.aneel.gov.br/Down〉. Acesso em: 23 jun. 2019.

AZEVED0, J. P. M.; NASCIMENTO, R. S.; SCHRAM, I. B. Energia eólica e os impactos ambientais: um estudo de revisão. Revista UNINGÁ, v. 51, n. 1, p. 101-106, 2017.

BABIKER, M. 0. Study on Solar Potential in Sudan - Challenges \& Implementation Approaches. 2020.

BIODINÂMICA. Estudo de Impacto Ambiental: Complexo eólico-solar Serra da Babilônia. Complexo eólico-solar Serra da Babilônia; Biodinâmica Engenharia e Meio Ambiente, v. 1, 2018, 770 p.

CABRAL, A. V. Análise multicritério em sistemas de informação geográfica para a localização de aterros sanitários. 0 caso da região sul da ilha de Santiago, Cabo Verde. 113 p. 2012. Dissertação (Mestrado em Gestão do Território, Área de Especialização em Detecção Remota e Sistema de Informação Geográfica), Faculdade de Ciências Sociais e Humanas, Universidade Nova de Lisboa, Lisboa. 2012.

CÂMARA, G.; DAVIS, C. Capítulo 1: Introdução. 5 p. Disponível em <http://www.dpi.inpe.br/gilberto/livro/introd/caplintroducao.pdf>. Acesso em: 23 jun. 2019.

CÂMARA, G.; ORTIZ, M. Sistema de Informações Geográficas para aplicações ambientais e cadastrais: uma visão geral. 1998. Disponível em: 〈http://www.dpi.inpe.br/geopro/trabalhos/analise.pdf〉. Acesso em: 23 jun. 2019.

CARRIÓN, J. A.; ESTRELLA, A. E.; DOLS, F. A.; RIDA0, A. R. The electricity production capacity of photovoltaic power plants and the selection of solar energy sites in Andalusia (Spain). Renewable Energy, n. 33, p. 545-552, 2008.

CARUSO JR. Relatório Ambiental Simplificado: Unidade Fotovoltaica Bonito 1 - Lagoa do Barro do Piauí/PI. Neoenergia, 2018, 451 p.

CELESTINO, V. S.; JULIÃO, R. P. Aplicação geográfica na identificação de áreas com potencial para gerar energia por fontes renováveis. Revista Brasileira de Cartografia, n. 69, v. 3, p. 473-494, 2017. ISSN: 1808-0936.

COOPER, J.; ROBERTS, M.; BRUCE, A. Spatial Analysis of Solar Potential in Melbourne. Sidnei: UNSW, 2018a. Disponível em: <https://www.researchgate.net/publication/324029235_Spatial_Analysis_of_Solar_Potential_in_Melbourne>. Acesso em: 13 jul. 2020.

COOPER, J.; ROBERTS, M.; BRUCE, A. Spatial Analysis of Solar Potential in Adelaide. Sidnei: UNSW, 2018b. doi: 10.13140/RG.2.2.15430.78404.

EASTMAN, J. R., 2012. IDRISI Selva Manual. Manual version 17. Worcester-MA: Clark University, Clark Lab, jun. 2012.

ECOLOGY BRASIL. Estudo de Impacto Ambiental: Linha de Transmissão 500/230 kV Parnaíba III - Tianguá II Teresina III e subestações associadas. Transmissora Serra de Ibiapaba, 2018, 1672 p.

EMPRESA DE PESQUISA ENERGÉTICA. Análise da inserção da Geração na matriz elétrica brasileira. Rio de Janeiro: mai. 2012.58 p.

EMPRESA DE PESQUISA ENERGÉTICA. Contrato de concessão $\mathbf{n}^{\mathbf{0}}$ 02/2018-ANEEL. 2018. Disponível em: < http://www2.aneel.gov.br/aplicacoes/siget/arq.cfm?arquivo=37647>. Acesso em: 20 abril. 2019.

EMPRESA DE PESQUISA ENERGÉTICA. Potencial dos recursos energéticos no horizonte 2050. Série Recursos Energéticos, Nota Técnica PR 04/18. Rio de Janeiro: EPE, 2018, 186 p.

ESCOLANO, Tania Oliveira. Análise de aptidão técnica e socioambiental de áreas para implantação de parques solares fotovoltaicos utilizando sistemas de informação geográfica na microrregião Campo Maior - PI. 99 p. 2019. 
Projeto final (Bacharelado em Engenharia Ambiental e Sanitária) - Faculdade de Engenharia, Universidade do Estado do Rio de Janeiro, Rio de Janeiro, 2019.

FERNANDES, T. M. F. Metodologias de aquisição de dados para o cálculo da radiação solar - aproveitamento da energia fotovoltaica no parque industrial de Lustosa. 2015. 82 f. Dissertação (Mestrado em Sistemas de Informação Geográfica e Ordenamento do Território) -Faculdade de Letras da Universidade do Porto, Porto, 2015.

FISHBURN, P. C. Additive Utilities with Incomplete Product Set: Applications to Priorities and Assignments. Baltimore: Journal of the Operations Research Society of America, v. 15, n. 3, 1967. doi:10.1287/opre.15.3.537.

GASPAROVIC, I.; GASPAROVIC, M.; MEDAK, D.; ZRINJSKI, M. Analysis of Solar Potential Spatial Data for Croatia. Geodetski List, v. 73, n. 1, p. 25-44, 2019.

GOMES, R. L.; CERQUEIRA, A. H.; STRENZEL, G. M. R.; PEREIRA, Y. C. Mapeamento do potencial solar para microgeração de energia elétrica: 0 caso da cidade de Ilhéus. Uberlândia: Sociedade \& Natureza, v. 31, p. 1-22. doi:10.14393/SNv31n1-2019-42302

INSTITUTO NACIONAL DE PESQUISAS ESPACIAIS. Atlas brasileiro de energia solar. 2. ed. São José dos Campos, 2017, $80 \mathrm{p.}$

JANKE, J. R. Multicriteria GIS modeling of wind and solar farms in Colorado. Renewable Energy, v. 35, p. 2228-2234, 2010 .

JOERIN, F.; THERIAULT, M.; MUSY, A. Using GIS and outranking multicriteria analysis for land use suitability assessment. International Journal of Geographical Information Systems, v. 2, n. 15, p. 153-174, 2001

JUNQUEIRA, R. C.; UTURBEY, W. Valoração econômica de impactos ambientais da energia solar fotovoltaica: um estudo de caso. Revista Brasileira de Energia Solar, v. 8, n. 1, p. 50-58, 2017.

KALE, R., e Yichun, X., 2005, Multi-Criteria Analysis using Preference Function Method for Developing a Rental Property Search Tool in GIS. In Proceedings of the ESRI User Conference.

KAURIA, L. Developing a global location optimization model for utility-scale solar power plant. 92 p. 2016. Dissertação (Mestrado em Geografia) - Universidade de Helsink, Helsínquia, 2016.

LEONZIO, G. Design and feasibility analysis of a Power-to-Gas plant in Germany. Journal of Cleaner Production, v. 162, n. 1, p. 609-623, 2017.

LIMA, J. C. 0.; BISPO, F. S. C.; RIFFEL, D. D. B. Comparação entre dados de radiação solar medidas por estações metereológicas automáticas no Estado de Sergipe com valores estimados a partir de imagens de satélite. In: SIMPÓSIO SERGIPANO DE ENERGIA SOLAR, 2016, Aracaju. Anais... Aracaju, 2016. 6 p.

MALCZEWSKI, J. GIS-based land-use suitability analysis: a critical overview. Progress in Planning, v. 62, p. 3-65, 2004.

MARTINI, L. E. Análise da irradiação solar em um campus universitário no sul do Brasil. 165 p. 2019. Dissertação (Mestrado em Engenharia Civil) - Universidade Federal de Santa Maria, Santa Maria, 2019.

REN21. Renewables 2018: Global status report. REN21, 2018. 326 p.

SANTOS, W. A. A.; ARAÚJ0, P. C. Geoprocessamento aplicado ao zoneamento geoambiental: subsídio à implantação de empreendimentos de geração de energia eólica. Revista de Geociências do Nordeste, v. 2, n. 2, p. 48-60, 2016.

TELLO ORTIZ, E. R. Sistemas fotovoltaicos e eólicos: metodologia para análise da complementaridade espacialtemporal com aplicação no dimensionamento e análise de risco financeiro. 178 p. 2014. Tese (Doutorado em Ciências) - Universidade de São Paulo, São Paulo, 2014.

TOLMASQUIM, M. T. (Coord.). Energia Renovável: Hidráulica, Biomassa, Eólica, Solar, Oceânica. Rio de Janeiro: EPE, 2016, 452 p. 
Escolano et al.

Revista Internacional de Ciências, v. 10, n. 02, p. 23-42, mai-ago, 2020 